\title{
Retóricas de la corporalidad en un archivo de relatos orales argentinos
}

\author{
Rhetoric expressions of corporality in Argentinean folk narrative
}

RMA

Dossier

\begin{abstract}
María Inés Palleiro
CONICET, Instituto de Filología y Literaturas Hispánicas "Dr. Amado Alonso", Universidad de Buenos Aires, Argentina. E-mail: inespalleiro@gmail.com
\end{abstract}

\begin{abstract}
Resumen
Me ocupo aquí de la retórica de la corporalidad en relatos orales que recopilé en investigaciones de campo en La Rioja, Argentina, relacionados con la mutilación corporal. Los agrupo en torno a matrices folklóricas, como modalidad de ordenamiento para identificar una poética de condensaciones metafóricas y desplazamientos metonímicos, en una tensión entre una lógica sinecdótica de fragmentación y la restauración simbólica de una completud corporal. Vinculo tal retórica de la corporalidad con la configuración de identidades sociales, en las matrices "El mundo de abajo", "Cairé" y "La niña sin brazos". Examino la recontextualización de estas matrices en el contexto riojano, y destaco el valor del trabajo etnográfico para detectar conexiones intertextuales con creencias locales, que remiten a un modelo cosmovisional.
\end{abstract}

Palabras-clave: corporalidad; retórica; narrativa folklórica; etnografía; Argentina

\begin{abstract}
The aim of this article is to analyze rhetoric expressions of corporality dealing with mutilation, in Argentinean folk narratives collected in an ethnographic research in La Rioja, Argentina. I select narrative versions of three folk matrices: "The lower world", "Cairé" ("Fear test: staying in a haunted house where corpse drops down chimney") and "The maiden without hands". I focus my attention in the tension between a synechdotic logic of corporal fragmentation and a metaphoric condensation of the body as a complete entity. I consider as well embodiment as a narrative construction dealing with discursive expressions of local beliefs.
\end{abstract}

Keywords: rhetoric; embodiment; folk narrative; ethnography; Argentina

\section{Algunas reflexiones sobre el trabajo etnográfico}

Guber (2001) plantea un acercamiento a la etnografía en su triple acepción de enfoque, método y texto, que recupera el valor del trabajo de campo. Considera esta disciplina como práctica de conocimiento que busca comprender fenómenos sociales desde la perspectiva de sus miembros destacando su agencialidad de sujetos sociales, y especifica que su rasgo distintivo es la descripción, entendida como método ajustado a la perspectiva nativa de los miembros de un grupo social, sin sustituir sus hechos, puntos de vista y valores por los del investigador. Como recuerda la semántica de la enunciación, toda descripción está teñida por la subjetividad de quien describe. Es así como tanto Guber como Rockwell $(1989,2008)$ consideran el problema de la reflexividad del investigador. Este enfoque que privilegia la perspectiva del "nativo" aparece como vía fecunda para el acceso a una cultura, si no olvidamos que también los investigadores somos "nativos" de un grupo, con nuestras representaciones y valores reflejados en los documentos que generamos.
Trabajo con textos establecidos como resultado de investigaciones de campo, para describir e interpretar algunos de sus rasgos distintivos a la luz de configuraciones culturales del contexto. Mi experiencia etnográfica en La Rioja se remonta a mis primeros viajes de campo, cuando encaré la realización de mi tesis doctoral -la primera en la carrera de Letras de la Universidad de Buenos Aires, luego de un oscuro período de cierre del doctorado, que aplicó métodos de análisis del discurso para el estudio de un corpus etnográfico-. En 1985, permanecí durante seis meses en la capital de La Rioja, desde donde me trasladé al interior, teniendo como sede de trabajo las escuelas primarias, denominadas "de concentración", porque allí confluían niños de distintas localidades del interior de la provincia. Configuré así un archivo de cuentos, leyendas, chistes, casos, sucedidos e historias que grabé en treinta y siete cassettes, digitalizadas más tarde en un archivo sonoro. Centré mi atención en el registro y transcripción de relatos, cuya selección y textualización constituyen de por sí una instancia interpretativa. En esta Tesis (defendida en 1991, y publicada en una síntesis en 1993 y en una reescritura actualizada en 2016) analicé 
los procesos de construcción ficcional de expresiones narrativas en contexto. En los años que siguieron, hasta 2000, viajé a la provincia con una periodicidad anual, hasta completar una investigación postdoctoral en la que agregué al archivo inicial de relatos recopilados en zonas rurales, manifestaciones de narrativa urbana. Este archivo me sirvió durante toda mi carrera como base de comparación con el material que recopilé en otras regiones de Argentina y del mundo, en distintos canales y soportes discursivos. Hasta 2013, continué visitando la zona, para constatar la vigencia de los relatos recopilados en mis primeros años de investigación. En esta oportunidad, revisito este material inicial para prestar atención a lo que Ong (1987) denomina "el componente somático" o corporal de la oralidad.

\section{El concepto de "archivo" y el principio narrativo}

Caracterizo el archivo en su acepción etimológica de arkhé o principio ordenador, que sirve como soporte y domiciliación de formas narrativas y que lleva implicada una interpretación sobre el material que se ordena (Derrida1997). Desde esta perspectiva, considero el relato folklórico como archivo, en tanto principio narrativo ordenador da cuenta de la memoria cultural de un grupo. Me remito a Bruner, quien considera la narración como principio cognitivo de articulación secuencial de la experiencia (Bruner 2003) y a Chafe (1990), quien llama la atención sobre la representación mental de la realidad en formas narrativas. La organización secuencial a la que alude Bruner puede a su vez ser deconstruida en bifurcaciones múltiples, similares a las de un hipertexto virtual, que reproducen los itinerarios flexibles del recuerdo (Palleiro 2004). Entiendo la tradición en su dimensión procesual de resignificación del pasado desde el presente (Handler y Linnekin 1984) y abordo la narrativa tradicional con un enfoque comunicativo, que subraya el trabajo poético sobre el mensaje (Jakobson 1964). Me remito al concepto de intertextualidad genérica (Bajtín 1979), para una aproximación a los relatos como espacios de convergencia de estrategias discursivas heterogéneas y. presto atención a las brechas intertextuales (Briggs y Bauman 1992) entre el ajuste de cada narrador a un canon genérico y su actuación personal, que transforma dicho canon con un estilo propio.

\section{La narratividad y el enfoque genético}

Tomo en cuenta los aportes de la genética textual, que pone el acento en las variantes textuales, mediante el estudio de correcciones y tachaduras de manuscritos (Grésillon 1994). Las variantes son también eje de la oralidad folklórica, como señala Menéndez Pidal (1974) y reafirma Chertudi (1978) al sostener que el cuento folklórico vive en variantes en la oralidad. Tales variantes remiten a modificaciones de patrones temáticos denominados "tipos" y "motivos". El motivo es la unidad temática mínima del relato folklórico, y el conjunto de motivos configura un "tipo" temático. Los tipos fueron codificados en Índices Generales por Aarne, Thompson y Uther, y los motivos en el Índice de Thompson, con un sistema alfanumérico que utilizaré en este trabajo. También desde una perspectiva genética, Lebrave (1990:156) caracteriza correcciones y variantes de manuscritos como operaciones materiales del acto de escritura, clasificadas en adiciones, supresiones, sustituciones y desplazamientos. Por su parte, Grésillon (1994:242) Ilama la atención sobre la importancia del avant-texte o pre-texto, al que define como "conjunto de todos los testimonios genéticos escritos conservados de una obra o de un proyecto de escritura". Reformulo estos conceptos para la narración folklórica, alrededor de la noción de "matriz genética" a la que considero como dispositivo pretextual del relato folklórico, generador de distintos recorridos en contextos diversos (Palleiro 2004).

Desde una óptica formalista, Mukarovsky (1977) destaca la relevancia semántica de los "detalles" como unidades básicas de la composición folklórica. Como afirmé en trabajos anteriores (Palleiro 2004), estas modificaciones de detalles son ejes de transformación contextual de estereotipos folklóricos. Desde la teoría informática, Nelson caracteriza el hipertexto como "texto que se bifurca", compuesto por "una serie de bloques textuales conectados entre sí por nexos que forman diferentes itinerarios para el usuario" (Nelson 1992: 2-3. La traducción es mía). Con este enfoque, el relato folklórico puede ser considerado como conjunto de bloques textuales constituido por unidades mínimas independientes, conectadas mediante nexos flexibles. A partir de estos conceptos, defino la matriz folklórica como patrón de configuración del relato, constituido por un conjunto de regularidades temáticas, compositivas y estilísticas comunes a diversas manifestaciones narrativas, identificadas mediante la confrontación intertextual. Las transformaciones de la matriz se presentan como adiciones, supresiones, sustituciones y desplazamientos, que dan lugar a bifurcaciones virtualmente infinitas, análogas a la estructura diseminativa de un hipertexto virtual. Cada matriz, almacenada en la memoria de los narradores, funciona como núcleo generador de realizaciones textuales diferentes, cuyo contenido semántico se relaciona con identidades colectivas (Palleiro 2004). Los parámetros de tema, composición y estilo tienen como base las categorías propuestas por Bajtín (op. cit.) para delimitar géneros discursivos.

\section{El concepto de 'performance'}

Austin (1982) relaciona la dimensión pragmática del lenguaje con las acciones producidas en el contexto a partir de un acto de discurso ${ }^{1}$ y Schechner (2000), en una reflexión sobre el teatro de vanguardia, vincula la

\footnotetext{
Para una profundización acerca de la teoría de los actos de habla, véase Palleiro, Di Marzo, Fabaro, Luque, Miño, Muñoz y Suárez Lissi (2008).
} 
performance con la dinámica entre entretenimiento y eficacia, referida a la dia entre representación espectacularizada de la vida social en escena y el efecto transformador de las prácticas artísticas. Bauman (1975) considera también la performance con praxis cuyo rasgo distintivo es el despliegue de un mensaje estéticamente marcado, ante una audiencia que evalúa su eficacia comunicativa. Turner (1986 y 1988) subraya la dimensión teatral en géneros folklóricos como el rito, entendido como reiteración secuencial de acciones de acuerdo con ciertas reglas. Tal reiteración da lugar a la cristalización de un patrón discursivo puesto en acto en situaciones precisas, para producir efectos sobre el contexto (Rappaport 1992, Palleiro comp. 2011). Múltiples códigos operan en eventos performativos, que incluyen no solo el arte verbal sino también el código corporal, en una conjunción multisemiótica. La comunicación folklórica constituye una expresión estética espontánea de identidades colectivas en un entorno físico, social y cultural, que pone en acto un despliegue sígnico de la memoria social, en una elaboración poética individual de cada performer (Palleiro 2008). Cada emisor - ya se trate del practicante de un rito, narrador o artesano - despliega ante los receptores un mensaje en un contexto, al que imprime su sello personal en una actuación o performance, tendiente a lograr una recepción adecuada (Bauman 2004). Estos procesos dan lugar a la resignificación de un sentido de pertenencia, en el que juegan un rol preponderante las creencias.

\section{La dimensión de la corporalidad y su retórica}

El eje desde el cual propongo una entrada a mi archivo, analizado en otros trabajos desde ángulos diferentes (Palleiro en Fischman y Hartmann 2007, Palleiro 2008, Palleiro 2016) es el de las representaciones discursivas de la corporalidad, que dan cuenta de configuraciones culturales. La corporalidad ha sido objeto de reflexión de la antropología cultural y la sociología (Mauss 2006, Csordas 2011, Le Breton 2002, Citro 2011). Siglos de dualismo racionalista llevaron a que, en la modernidad occidental, el cuerpo fuese visto como objeto, disociado del alma y la razón, pero nuevas líneas de pensamiento lograron expresar el rol significativo de la corporalidad en las culturas contemporáneas. Se destacan en estos debates dos tensiones. La primera, entre cuerpo y embodiment, como corporización cultural de una entidad biológica y la segunda, entre el embodiment y la del cuerpo representado como texto, propia de un abordaje semiótico (Krmpotic y Palleiro 2016). Mi abordaje se relaciona con esta última perspectiva. Para una aproximación semiótica a la corporalidad, tomo como base los planteos de Verón (1988: 42), quien afirma que todo discurso es de cuerpos actuantes. Por su parte, Csordas (op. cit.) se refiere a los "modos somáticos de atención" como maneras culturalmente elaboradas de prestar atención al propio cuerpo, que suponen la presencia corporizada de otros. Estos aportes han sido incluidos en Citro (2011). Pongo énfasis en la noción del cuidado, que considera al sujeto en su capacidad de relacionamiento que lo lleva a necesitar del otro, en la incompleta unidad del existir (Krmpotic 2011). La ausencia de completud tiene su expresión discursiva en el principio metonímico, asociado con la fragmentación y la falta (Le Guern 1985, Le Galliot 1981). Dicha falta tiene como contracara el principio metafórico, en una condensación que reúne significaciones distintas en un mismo significante, tendiente a recuperar la completud.

La narratividad, en tanto estructura secuencial de la experiencia, proporciona un formato apto para la articulación de la corporalidad con creencias sociales que involucran un concepto del cuerpo y su cuidado propio de cada cultura. En este sentido, resultan esclarecedores los planteos de Labov y Waletzky (1967) sobre la narrativa personal de experiencias individuales, como vehículo de expresión de identidades sociales.

Para la semiótica, cobra relevancias la clasificación peirciana de los signos, según la relación con el referente, en íconos, índices y símbolos. Para Peirce (1987), el ícono tiene una relación de analogía o semejanza con el objeto; el índice, una relación de existencia (vinculada con la contigüidad o proximidad existencial), mientras que el símbolo tiene una relación convencional de valor. Trabajo con la relación metonímica de contigüidad existencial de signos corporales, que instauran una lógica sinecdótica entre el todo y la parte. Este juego tiene su anclaje indicial en el cuerpo, como capa metonímica que instaura relaciones de existencia. Verón (op. cit.: 44-45).) se refiere así al cuerpo como capa metonímica de producción del sentido, que emite signos de modo consciente e inconsciente. Efectivamente, el cuerpo jamás puede desprenderse de la existencia histórica del sujeto y su dimensión significante tiene que ver con la expresión de múltiples aspectos de esta existencia, en una dinámica entre parte y todo, ya que las distintas partes del cuerpo tienen dimensiones expresivas diferentes, atravesadas por el universo simbólico de la cultura, producto de un disciplinamiento social. La corporalidad tiene también una dimensión icónica de la imagen que cada cuerpo transmite y una dimensión simbólica, del conjunto de significaciones que aglutina cada representación corporal, como emblema metafórico de valores sociales. Es así como Merleau Ponty afirma que el espacio corporal está cargado de significaciones que tienen que ver con una forma de vivir en el mundo, expresadas espontáneamente sin un discurso verbal. El cuerpo está convencionalizado por una cultura dentro de la cual la subjetividad se construye y despliega gracias a un intercambio intersubjetivo, y. la concepción de la corporalidad de cada cultura se relaciona con creencias y estilos de vida.

Lo corporal da lugar a un despliegue performativo, materializado, entre otras manifestaciones, en hechos de narración. De este modo se llega a construir un 
estereotipo corporal, reproducido en extensiones como la vestimenta, y reconstruido en el discurso del relato.

La dimensión retórica se vincula con estrategias discursivas de persuasión (Lausberg 1975), y con un trabajo poético sobre el mensaje que, en el caso de discursos de, en y sobre el cuerpo, es un mensaje corporal. Parafraseando a Mc Luhan, el cuerpo es el mensaje, que expresa mucho más de lo que se propone. Todo discurso tiene un componente somático o corporal, con su retórica propia, caracterizada por procesos metafóricos y metonímicos.

Recurro a la caracterización de la sinécdoque y la metonimia aportada por Jakobson (1956), quien, en un estudio sobre trastornos afásicos, vincula las operaciones metonímicas con alteraciones en la combinación, que remiten al eje lingüístico de las contigüidades. Le Guern (op. cit.) considera la sinécdoque como tipo particular de metonimia. Un enfoque psicoanalítico relaciona tales operaciones con una dinámica entre completud y falta generadora del deseo, y caracteriza la metonimia como manifestación discursiva de un desplazamiento de la "cadena inconsciente" (Le Galliot op. cit.: 74-75). En este sentido, la metonimia puede ser considerada como huella indicial del deseo de lo que falta. Desde este enfoque, el principio metonímico puede vincularse con la dinámica de la falta, el desorden, la enfermedad y la muerte, que tiene como contrapartida la salud y la cura como procesos metafóricos de restauración totalizadora.

En el análisis de los relatos, relacionaré estos conceptos con una lógica sinecdótica (Briggs 2001), generadora de un movimiento entre tal desintegración dispersiva y la integración totalizadora. Es así como la enfermedad, entendida como ausencia de completud tiene su expresión discursiva en el principio metonímico, asociado con la fragmentación y la falta. En un estudio sobre la narrativa epidemiológica entre los Waraos del delta venezolano, Briggs (op. cit.) se ocupa de relatos sobre el cólera en época de la Guerra del Golfo, que impactaron en este grupo indígena. Destaca la lógica sinecdótica de la narrativa epidemiológica, vinculada con una modalidad cognitiva que permite presentar el efecto por la causa o el todo por la parte. Tal lógica sinecdótica intenta explicar un hecho global como el impacto del cólera a partir de sucesos particulares como la difusión de esta enfermedad entre los Waraos, por un mecanismo de contagio. Este mecanismo da lugar a una retórica de la globalización (Briggs op. cit.), extensible a toda construcción discursiva de la enfermedad, asociada con la esfera semántica de la falta de salud y la mutilación corporal, cuya contrapartida es el concepto de "salud" como integración totalizadora, asociada con el ajuste a un orden social.

El eje genético de los relatos es el de las representaciones de la enfermedad y la herida como procesos de quiebre. El correlato de este quiebre es la atención y la cura para restablecer el "estado oculto de la salud" (Gadamer
1996) como metáfora de un orden cosmogónico. Mary Douglas (1988) se ocupa de la construcción social del terapeuta como guía hacia una realidad diferente, y reflexiona sobre lo cruento de modos de curación que recurren a acciones como cortar carne y huesos o derramar sangre, a los que confronta con modalidades terapéuticas menos invasivas como las terapias holísticas. Tales aspectos se ven reflejados en los relatos, en los que el derramamiento de sangre o la caída de miembros de un cuerpo son presentados como signos indiciales de una falta, traducida en quiebre o desorden restaurado por mediación de pruebas, como ocurre en "Media Res", "Cairé" y "La niña sin brazos".

\section{La dimensión de las creencias y de las identidades sociales}

Considero las creencias, desde una perspectiva semiótica, como expresiones relativizadas de certeza, en las que el valor de verdad depende de un posicionamiento subjetivo o consenso intersubjetivo (Greimas \& Courtés 1982), y subrayo que el cuerpo, en tanto construcción cultural, se constituye como soporte de identidades, semiotizaciones y escenificaciones performativas (Le Breton 1995). Kaliman (2006) caracteriza la identidad como autoadscripción a un colectivo, generalizada entre sus miembros. Toda identidad necesita del otro para constituirse y es, por lo tanto, social. Recupero la dimensión comunicativa del Folklore, que se interesa por la construcción diferencial de las identidades mediante una elaboración estética de mensajes, encaminada a asegurar su eficaz recepción (Bauman 1975). Las creencias y rituales, en tanto configuraciones culturales expresados a través de la corporalidad, remiten al concepto de "cultura" que, para García Canclini (2001), opera con la lógica de la heterogeneidad. Estos aspectos están expresados en un despliegue discursivo de cuerpos actuantes, puesto en acto por en personas desdobladas en narradores, que crean personajes de un universo ficcional.

Sobre la base de estos conceptos, me ocuparé de representaciones narrativas de la corporalidad mutilada y recuperada.

\section{La fragmentación corporal y el trato con el diablo: "Media Res" y sus intertextos}

La fragmentación corporal está presente en "Media Res", que recogí en la localidad riojana de Villa Mazán, en 1987, de boca de María Isabel Flores, de 17 años. En trabajos anteriores (Palleiro en Fischman y Hartmann op. cit.), comenté ya este relato, ordenado en torno a la matriz "El mundo de abajo", publicado en Palleiro (2011), que revisito desde la lógica de la fragmentación corporal:

"Había una vez un hombre que tenía una mujer y dos hijos. Y que su mujer estaba embarazada, y que se le había antojado comer carne de guanaco Entonces, salió 
a buscar un guanaco. (...) Se encuentra con otro hombre, todo de negro, en una mula negra, que lo habla, y le dice que le dé al hijo menor (...) a cambio del guanaco. $Y$ que la mujer ha tenido el hijo. Y que el hombre le ha llevado (...) Que el diablo, era, el que le ha pedido al hijo a cambio del guanaco (...) Y que se lo ha entregado (...). Y que después, cuando se ha dado cuenta que era el diablo, que se lo ha vuelto a quitar. Y que han estado forcejeando, así, y que después, lo han partido (...) y que era toda una media res [La narradora realiza ademanes de forcejeo, y de partir un objeto por la mitad, con sus brazos y manos]

(...)Y ya era grande, y le dice al padre: -¡Papá, yo me voy a ir a rodar tierra! (...) Y que (...) contrata a (...) tres hombres de peones, para que trabajen con él. $Y$ él compra fincas con animales: vacas, ovejas, cabritos y todo (...)Y que un día, cuando ha llegado el patrón (...) le dice uno:-¡Patrón, patrón, ha venido un hombre, y nos ha robado la comida! (...)Y que entonces va el patrón, y saca la cortaplumas, y le corta una oreja (...) Y (...) han seguido el rastro, así, porque iba la sangre(...)del hombre (...)y han llegado hasta una piedra. Y que esa piedra era la entrada de un pozo. Y después, dice que han hecho unas sogas largas (...)con la tela de los cinturones de los tres peones (...) Y que bajo de esa piedra (...)era el infierno. Y (...) se mete uno. Que baja por la soga, y que llega en una primera parte de abajo, que había unas llamas. Y que sigue bajando, y en la segunda parte, que había unas fieras. Y después, más abajo, que había un lago de aguas muy calientes. Y que al llegar ahí, que ya tiraba de la cuerda, así, para que lo levantaran para arriba, porque no podía cruzar (...) Y que entonces, después, se mete (...) el Media Res. Y dice que pasa por las llamas, y por las fieras. Y que después, cruza el lago de agua muy caliente. $Y$ que del otro lado del lago, que estaban unos castillos. Y que en cada castillo, había una chica (...) Que (...) eran los castillos del diablo (...) Y (...) que ahí ha llegado el diablo (...)Y que entonces el Media Res (...)se ha escapado del castillo por una puerta de atrás, con la chica. (...)Y después, que va para el otro castillo (...) y ahí estaba encerrada otra chica (...) Y después, que llega al tercer castillo. $Y$ que se encuentra con otra chica, que era más linda que las otras dos. Y (...) que la saca, también (...) Y diai, que el Media Res se ha vuelto pa' buscarlo al hombre que lo había dejado con una sola oreja. Que era un diablo (...) y que por eso se había metido en el pozo del infierno (...)Entonces, que el diablo lo ve al Media Res, y le dice:-¡Dame la oreja, por favor! (...) Entonces, que le dice el Media Res (...)-jHaceme un castillito de oro, y te voy a poner bien la oreja! Entonces, le hace el castillo de oro, el diablo (...) lleno de habitaciones, con sirvientes, y autos, todo. Y que entonces, que le dice al diablo: -jAhora, entregame la media res, o no te pongo bien la oreja! $Y$ que el diablo se la entrega, y él le pone bien la oreja. $Y$ que entonces, ya andaba entero, el Media Res (...) Y que entonces, que la ha mandado traer a la tercera chica, y que se quedó a vivir con ella en el castillo de oro. Y diái, han vivido felices (...)"
La estructura compositiva tiene como eje la adición episódica de unidades (Mukarovsky op. cit.), cuyo elemento cohesivo es la presencia de un mismo protagonista.La fragmentación metonímica está asociada con el trato con el diablo, que remite a las creencias locales. La fragmentación está presentada desde la primera secuencia, en la que se presenta el trato como desencadenante de la desintegración corporal del héroe, que debe repararse mediante la acción narrativa. El nombre "Media Res", alude al juego sinecdótico entre todo y parte, vinculado con el trato con el diablo celebrado por su padre ("Que el diablo ... le ha pedido el hijo (...). y que han estado forcejeando, así, y que después, lo han partido, así, al hijo, y que era todo una media res [La narradora realiza gestos y ademanes de forcejeo, simulando partir un objeto por la mitad con sus brazos y manos]"). El proceso metonímico de división del todo en partes está reforzada por la deixis lingüística ("así") y el código mímico-gestual, que recurre a la corporalidad, y actualiza el conflicto narrado en el aquí y ahora del contexto enunciativo. El juego metonímico constituye un recurso retórico frecuente en el relato folklórico, presente en otros relatos como "Mediopollo" (Palleiro 2011). La vinculación del trato con el diablo con creencias locales se advierte en la confrontación intertextual con casos, historias y ritos que recogí en mi investigación etnográfica. Entre estos materiales se cuenta una entrevista al artesano Marino Córdoba sobre la Salamanca, ceremonia constituida por "pasos" o instancias rituales cuyo climax es el trato con el diablo. En un viaje de campo a La Rioja, tuve la oportunidad de entrevistar a este artesano, nativo de Agua Blanca, autor de una serie de estatuillas cerámicas sobre esta ceremonia ritual. La entrevista, realizada en agosto de 1991 en su taller, tuvo como eje la mostración visual de estatuillas que representaban los pasos rituales. En trabajos anteriores (Palleiro en Fischman y Hartmann op. cit.) analicé esta entrevista, que hoy retomo desde la perspectiva de la corporalidad mutilada. Entre las estatuillas que mostró Marino, hoy exhibidas en el Museo Folklórico de La Rioja, se cuenta la de la representación icónica del diablo con la apariencia zoomorfa de un chivo:

"...la Salamanca es el encuentro con el demonio (...) y viene el diablo, en forma de chivo negro, o de chancho, de perro, de cualquier animal [El artesano muestra una estatuilla del diablo representado bajo la forma de un chivo]" (Córdoba en Palleiro 2016: 54).

Esta transformación zoomorfa resulta similar a la de Media Res, donde un niño es sustituido por un guanaco. Tal sustitución aparece también en casos locales como el de "un matrimonio que no podía tener hijos", narrado por Andrea Carrizo, de 14 años, en la localidad riojana de Suriyaco, en 1987. Este "caso" refiere el trato con el diablo para tener un hijo celebrado por un lugareño, al que el diablo le entrega como hijo un guanaco. El relato, presentado por Carrizo como acontecimiento real, tiene como point (Labov \& Waletzky op. cit.) el mismo tópico 
del trato con el diablo:

"Había un matrimonio (...) que había hecho un trato con el diablo para tener un hijo... y el diablo le ha dicho que [la mujer] iba a quedar embarazada (...) y que cuando ha tenido el hijo, que le ha salido un guanaco (...)Y que eso le ha pasado por tener tratos con el diablo, que ha tenido un hijo guanaco..."

En la confrontación intertextual, se advierten similitudes entre los dos relatos, dado que ambos mencionan la identificación del demonio con un guanaco. Las representaciones zoomorfas del diablo tienen lugar también en la Salamanca, lo cual evidencia la interrelación entre "cuento", "caso" y "rito". El juego metonímico, a la luz de la confrontación intertextual, se vincula con creencias en las que la fragmentación corporal adquiere connotaciones rituales. Es así como Marino alude a tal fragmentación como parte constitutiva de la Salamanca, en un juego sinecdótico de disgregación de partes:

"... cuando se encuentra una mujer desnuda en el campo, sin cabeza, que es la bruja (...) que se desprendió del cuerpo la cabeza (...) ya está iniciada (...) y sale (...)a la Salamanca (...) al encuentro con el demonio" (Córdoba en Palleiro 2016: 54).

Tal resignificación del discurso ficcional de "Media Res" en términos de creencia lo convierte en expresión de la identidad diferencial del grupo (Bauman 1974). En la relación del rito, Marino presenta al demonio mediante un proceso metonímico de disgregación corporal (Le Guern op. cit.) que tiene su correlato en la ruptura de un orden simbólico establecido, representado metafóricamente por la cruz invertida. Tal representación se conecta con la primera prueba, en la que "está Cristo... cabeza abajo, y tienen que pisotearlo" como "paso" inicial de la Salamanca, similar a la ruptura del orden por el trato con el diablo de "Media Res".

El encuentro con el demonio está asociado con el tópico de las metamorfosis zoomorfas, que son una expresión metafórica de la totalidad del rito. En el plano icónico, dichas transformaciones están plasmadas en el efecto de movimiento de figuras como el diablo Zupay, que conserva en su organización visual la morfología humana de cuerpo y cabeza, combinada con figuraciones zoomorfas como la de un león y un chivo:

La misma fragmentación expresada por Marino en el discurso icónico se encuentra desplegada en "Media Res" a través del discurso verbal, en el cual el desequilibrio es restaurado por mediación de una serie de pruebas. La carencia planteada por este proceso metonímico se restaura de este modo por mediación de "pruebas" (Greimas 1976), que el protagonista debe sortear para conseguir la "media res" faltante. La carencia inicial asociada con la mutilación, que en el esquema de Propp (1972) se denomina función Ca, está seguida de la macrosecuencia de las "pruebas" u obstáculos que debe superar el héroe en el Inframundo. En "Media Res", la fragmentación es presentada como castigo por no cumplir con un trato con el diablo. También en la Salamanca, Marino asocia los "castigos" con metamorfosis zoomorfas, regidas por la lógica sinecdótica de la mutilación, que tiene como contrapartida la necesidad de cura. Las pruebas remiten al estereotipo temático de las "tareas imposibles" ("Impossible tasks", en términos de Aarne-Thompson-Uther). Tales tareas forman parte de una matriz narrativa que tiene como regularidad compositiva las secuencias de "ruptura" y "restauración del orden". La macrosecuencia de pruebas en el mundo subterráneo para rescatar a las princesas tiene como estrategia retórica, además de la metonimia, la hipérbole o exageración, ajustada a la "ley del tres" del estilo folklórico (Olrik 1992). Las pruebas consisten en atravesar un río de llamas de fuego, enfrentarse con fieras y cruzar un lago de aguas hirvientes, en una gradación de complejidad, que las localiza en un espacio cada vez más profundo ("...Que para abajo...en la primera parte... había unas llamas... y en la segunda... unas fieras...y más abajo... un lago de aguas muy calientes...y estaban unos castillos..."). Tal modalidad compositiva guarda un vínculo intertextual con la relación de Marino, que menciona pruebas similares:

“... [la prueba]del agua y del fuego...que hay que pasar los pies por una fogata...y meterse después en un charco de agua...y que no se tienen que escapar...porque si se

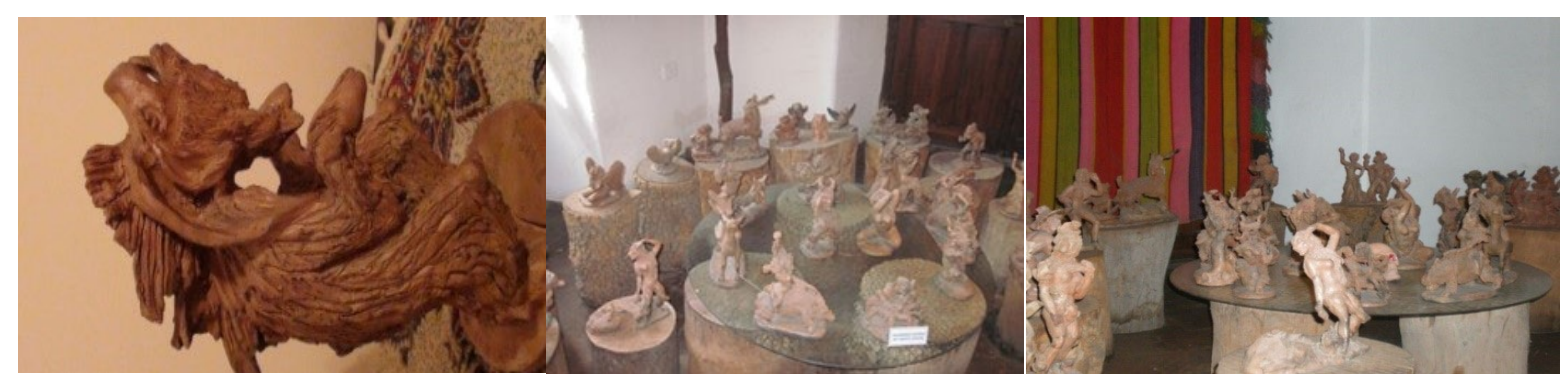

Figura 1. De izquierda a derecha: 1) el diablo Zupay de la colección privada de María Inés Palleiro, 2) y 3) la Salamanca en el Museo Folklórico de La Rioja (foto gentileza Analía Canale)

Figure 1. From left to right: 1) the devil Zupay from the private collection of María Inés Palleiro, 2) and 3) the Salamanca in the Folkloric Museum of La Rioja (photo courtesy Analía Canale) 
escapan, que se caen en un güeco sin fondo. Y que ese güeco sin fondo, que va a parar al mismo infierno, y que ahí están los diablos que viven en unas como celdas, ahí, como ser en distintos pisos, por debajo de la tierra" (Córdoba en Palleiro 2016:57)"

Tanto el relato "Media Res" como el de Marino despliegan una topografía del Inframundo, mediante descripciones con imágenes visuales que introducen la dimensión espacial en la sucesión de acciones (Genette 1974). Tales coincidencias resignifican el cuento, a la luz del rito que remite a creencias colectivas. Es así como las pruebas adquieren así el doble valor de tareas y pasos rituales.

La incorporación del contexto se evidencia en la alusión a relaciones laborales entre patrón y peones ("....y el Media Res... los contrató a los tres hombres de peones, para que trabajen... Y él compra fincas con animales: vacas, ovejas, cabritos, y todo... iban a trabajar... y se queda el patrón...").La descripción incorpora el espacio local, convertido en "paisaje textual" (Venturoli 2004) mediante la enumeración de distintas clases de ganado y de fincas de la región.

Entre las transformaciones contextuales, sobresale la incorporación del "auto" como recompensa exigida por el héroe en reconocimiento de su triunfo, que constituye un "recurso de actualización" (Palleiro 1992) de la matriz general. Esta alusión introduce una anacronía narrativa con respecto a la ambientación en un mundo de castillos y princesas, de connotaciones medievales. La secuencia final corresponde, en términos de Greimas (1976), a la "restauración del orden", representada por el casamiento del protagonista.Tal restauración está asociada con la reintegración de la completud corporal, dada por la recuperación de la media res, que remite a la completud holística mencionada por Gadamer al referirse al "estado oculto" de la salud. Tal completud aparece como consecuencia de la reparación del quiebre en pedazos, al que Douglas asocia con modalidades de curación.

"Media Res" incluye un corolario moralizante, propio del enxemplo medieval. El enxemplo es un relato "ancilar"; esto es, dependiente de otra estructura discursiva, con el valor de prueba argumentativa en apoyo de una enseñanza moral (Welter 1927). Tal carácter moralizante aparece reflejado en una "coda" (Labov \& Waletzky op. cit.) que establece una relación de causa-efecto entre el "trato" con el diablo y el efecto de tener un hijo guanaco. Cabe establecer una distinción entre el concepto de "pecado" de la teología moral católica, asociada con el universo cultural hispánico, y la falta de la fragmentación metonímica de la Salamanca, reflejada también en "Media Res", que remite a un universo de culturas indígenas. El "pecado" es definido por pensadores católicos como Pieper (1998), a partir de la misma dinámica metonímica de la falta mencionada en las versiones orales y en el discurso de Marino. En el canon católico, esta falta se vincula con la ruptura de un orden trascendente, producido a partir de un "quebrantamiento de una norma absoluta, que trasciende al hombre [quien] es un ser de tal índole, que puede hacerse culpable" (Pieper op. cit.: 23-40). Resulta evidente la similitud con la "ruptura del orden" greimasiano, relacionado en la moral católica con la culpa por la ruptura de una norma absoluta asociada con un orden trascendente. Por el contrario, Marino alude a un desorden inmanente, expresado a través de una retórica de la desintegración. Por su parte, "Media Res" presenta a un héroe que logra restaurar una situación de falta, mediante acciones prodigiosas en el Inframundo. Tal restauración apunta a reparar la falta o carencia inicial, para un goce estético, mediante la restauración de una corporalidad fragmentada. El corolario moralizante es mínimo, y el énfasis está puesto en la trama, que tiene por objeto entretener al auditorio con la narración de hazañas prodigiosas.

\section{"Cairé": la dinámica de la fragmentación corporal y el tópico del coraje}

El tópico de la fragmentación corporal como resultado de una maldición demoníaca aparece también en la matriz "Cairé", que tiene elementos temáticos comunes con el motivo H 1411. 1 de Thompson: Fear test: staying in a haunted house where corpse drops piecemeal down chimney. Esta versión, narrada por César Soria en setiembre de 1986, en la localidad riojana de La Maravilla., tiene como rasgo distintivo la localización en un ámbito real. Tal localización es presentada en la cláusula inicial y reforzada en la coda final, en un procedimiento de enmarcado: "Mi abuelo (...) me ha contado que (...) cuando él era chico (...) un gaucho se ha ido para un ranchito de La Maravilla (...) Esto ha pasado cuando el abuelo era chico (...) allá, en un ranchito de La Maravilla". Esta ubicación se relaciona con la clasificación del relato como caso real, que genera una acumulación aditiva de detalles contextuales, orientados a crear un efecto de realidad, subrayado por marcas deícticas que remiten a un referente espaciotemporal, y por operadores de modalización asertiva: " ... que es cierto (...) que esto ha pasado cuando el abuelo era chico, hace muchos años (...)en un ranchito, allá, en el canal La Maravilla..."

En esta versión, el motivo está vinculado con una relación genealógica, asociada con la maldición de "los Aguirre", que "eran condenados por el diablo". El point es la pelea del gaucho con el diablo, quien adopta una configuración antropomorfa y cae en pedazos, en un juego metonímico de disgregación, desde lo alto de un techo de "un ranchito" de "La Maravilla". El protagonista es este "gaucho" que lucha contra esta aparición del diablo personificado:

"Que (...) un gaucho (...) se ha ido para un ranchito (...) y que a la noche (...) ha empezado a caer una pierna, y la otra mitá (...) un brazo, y después el otro (...) Qu' era el 
diablo, el que ha caído (...) Que se han puesto a pelear, el gaucho, con el diablo. Y que al último, le ha plantado el cuchillo (...) el gaucho, al diablo, y se ha desaparecido" (Soria en Palleiro 2011)

La versión presenta una identificación animista del diablo con un paisano lugareño, capaz de ocasionar un "daño" y condenar a toda una genealogía. Esta identificación antropomorfa está dada mediante una condensación metafórica, que remite a la cosmovisión local. El eje es la representación antropomorfa del diablo, vencido por el "gaucho" gracias a su coraje. Puede advertirse en esta representación la misma lógica sinecdótica de fragmentación corporal, asociada con una cosmovisión que combina elementos del universo cultural hispanocatólico con otros de raigambre indígena.

\section{"La niña sin brazos": metonimia y mutilación corporal}

En "La niña sin brazos", narrada por Fortunata de Fuente, ama de casa mayor de 60 años, en la localidad riojana de Pinchas, departamento Castro Barros, el 14/VII/1987², la fragmentación corporal está asociada también con la intervención de seres sobrenaturales relacionados con la esfera semántica del mal, que son "unas brujas". El relato, clasificado por la narradora como "cuento" ubicado en la dimensión de lo fictivo, ordenado alrededor de la matriz "La niña sin brazos" tiene elementos comunes con el tipo 706 de Aarne-Thompson-Uther, "The maiden without hands":

"Había un rey que tenía tres hijas. Y un día, que le dice a la mayor: - (...)- ¿Cuál es el gusto de los gustos y el sabor de los sabores? - ¡No sé, mi padre!- (...) La llama a la segunda, y (...) no sabía, tampoco. La llama a la shulca (...)le contesta: - ¡Mi padre, el gusto de los gustos es la sal, y el sabor de los sabores es la grasa! (...)- ¡Pícara, que me adivinaste!- Y entonces (...) lo manda al negro que tenía, que la lleve al campo a la niña, y que le corte los brazos y le saque los ojos, y los lleve para él; y la deje a ella en el campo (...) Este negro no se animaba a sacarle los ojos a la niña (...) Y entonces, le sacó los ojos al perrito, y le cortó los brazos a ella (...)Y se fue, a llevarle para el rey (...)

Y la niña empezó andar, perdiendo sangre (...) Y ahí le había salido una zorrita, y le lamía la sangre (...) Y entonces, cicatrizó. Y la chica andaba con la zorrita (...) a las montañas (...) Y que un día, andaba un príncipe del rey, cazando. Y la vio a esta niña que andaba media desnuda y se escondía (...) y-¿Por qué se esconde? - dice. - ¡Porque yo- dice la chica -esta mala suerte tengo, que estoy desnuda (...)! - ¡No importa!- que dice el príncipe - ¡Suba al anca de mi caballo, y yo la voy llevar, y me voy casar con usted! (...) Y fue allá, y la presentó al rey, y se casó.

\footnotetext{
${ }^{2}$ Las versiones de esta matriz fueron publicadas en Palleiro (2011)
}

Y él atendía los moros de las batallas del rey (...) Y entonces, se fue a la batalla. (...) Y al tiempo ha nacido el niño; con una estrella en la frente (...) Y que entonces, el rey le hace una carta, avisándole (...) del nacimiento, y manda al negro (...) que la lleve. Pero el negro era medio tentado; y en el camino, había habido unas viejas brujas, y ellas lo han hecho chumar (...) Y le agarraron la carta, la leyeron, y la cambiaron. Le pusieron que había nacido (...) un monstruo, o un animal, un perro (...) Y el negro llevo la carta esa al príncipe del rey. Y cuando le dio la carta, el príncipe la vio. ¡Sea lo que sea, que lo críen, hasta que él venga (...) sea monstruo, sea perro; que lo tenga, que él venía! ${ }^{3}$

Y vino el negro, y se puso tomar otra vez (...) Y las brujas le sacaron la carta otra vez, y la leyeron, y la han vuelto a cambiar. Y le pusieron ¡Qué lo maten, o lo boten a los campos (...) al chiquito!

Y el negro ha llegado en la casa del rey, y se había olvidado la carta encima de la mesa, y la había leído la chica (...). Cuando amaneció (...) la chica habíase ido para los campos, con su zorrita y con el niñito (...) que ha llegado a la casa de una viejita muy pobre (...) Y después se fueron, con la zorrita. Y pasando de ahí, había un río con agua. -jPor aquí no podemos pasar, mamita! (...) -jNo te asustes!- que dice la zorrita -¡Sube en mí, y vamos pasar! (...) Y empiezan andar en el río. Y hacía una ladeada la zorra, y mete a la chica en el agua, y sale con la mano, la chica. Pasan otro poco, y se ladea para el otro lado, la zorrita; y sale con la otra mano (...). Y ya tenía las dos manos, que se le habían vuelto a formar (...).

Y seguían, y fueron a la casa de un ermitaño (...) que (...) ha querido (...) que le den al niño para ángel del cielo (...) Y mientras eso, que el padre del niño ya había vuelto de batallar con los moros, y se ha enterado que su mujer se había ido, y le siguió el rastro. Y fue (...) por la casa de la viejita pobre, y le dijo la viejita que ahí había ido una niña con una zorrita, con un niño con una estrella en la frente; pero que no tenía manos (...) Y le ha dicho también que ya se había vuelto a ir para el río, la niña. -¡No importa que no tenga manos, es ella la que busco! (...) Y ha seguido, nomás, el príncipe (...) para donde vivía el viejito ermitaño. Y llegó allá justo que el viejito lo enviaba para el cielo, al niñito. El príncipe lo vio a su hijo, y lo quiso tocar. $Y$ no se dejó tocar, el niñito: -¡No sos mi padre!- que le había dicho (...) Y el príncipe, entonces, se había puesto muy triste porque (...) el niñito solo conocía a su madre.Y claro, después se aclararon las cosas, y el príncipe los llevó de vuelta al niño y a la madre, con la zorrita.

Y (...) dice que le había dicho la zorrita: -¡Bueno!- dice, -¡Ahora, lo que tienen que hacer, es juntar leña, y quemar las viejas brujas que hicieron este mal! ¡Yo- dice -soy un

\footnotetext{
3 Nótese el uso del discurso indirecto libre, como rasgo de estilo característico de esta narradora.
} 
ángel enviado del cielo (...) ¡Hoy se termina mi permiso, y ya me voy, me vuelvo pa' 'I cielo!- que dice la zorrita. Y se hizo una paloma blanca, y se voló, la zorrita; se fue para el cielo (...)"

Esta matriz tiene como eje la fragmentación metonímica del cuerpo de una mujer presentada como mutilación sangrienta que requiere atención y cura, unida a una dinámica de sustituciones zoomorfas y antropomorfas, y a una antítesis entre esencia y apariencia. Tal cura está a cargo de un animal benéfico, que constituye la representación zoomorfa de fuerzas sobrenaturales. Las sustituciones de elementos de un dominio semántico por otro, como el cambio de los ojos de la niña por los de un perro, remiten a una cosmovisión que sostiene una interrelación entre los dominios de lo natural, lo sobrenatural y lo humano, propia de las creencias locales. En el nivel temático-compositivo, el relato presenta en la secuencia de apertura el castigo de un padre a la menor de tres hermanas por resolver una adivinanza con la mutilación de sus brazos. El castigo es cumplido por un sirviente, quien abandona a la protagonista en un descampado en donde aparecen la zorrita la ayuda a cicatrizar sus heridas, y un príncipe que se enamora, se casa y tiene un hijo con ella. Tal cicatrización se relaciona con las modalidades incruentas de cura a las que aludía Mary Douglas (op. cit.). En este sentido, la zorrita desempeña el rol de "auxiliar mágico" (Propp op. cit.) asociado con su capacidad terapéutica, y representa el doble animal de una entidad divina. En la secuencia de las sustituciones zoomorfas del niño por distintos animales, se alude a que el príncipe parte a luchar contra moros, y esta referencia constituye un indicio de la filiación hispánica del relato. Una secuencia relevante es la del cambio del hijo por un animal de características monstruosas a cargo de las brujas, y de una carta del príncipe por otra que da la falsa orden de matar a su hijo. Estos cambios de seres humanos por animales guardan analogía con el rito de la Salamanca. La falsa orden genera la secuencia huida de la protagonista y la zorrita, con la que atraviesa un río de propiedades curativas. Allí recupera sus manos, en una restauración de la completud quebrada por su mutilación inicial. El regreso del príncipe está asociado con la restauración del orden. Se intercala aquí el motivo folklórico del reconocimiento, según el cual, como Astíanax en la llíada, el niño no reconoce a su padre guerrero. Con el rescate de su esposa y su hijo de las manos de un ermitaño, y la quema a las brujas, queda restaurado el desorden inicial, asociado con la fragmentación metonímica de las manos de la protagonista. Las secuencias están unidas entre sí por nexos flexibles, que favorecen la incorporación de elementos de la cultura local.

En el nivel retórico, sobresale el diálogo que da vivacidad a la narración, y el uso de enunciados referidos que incluyen el discurso indirecto libre. El contrapunto polifónico, así como el empleo de recursos de contextualización en el ámbito rural de un "campo" similar al lugar de narración, actualizan el conflicto narrado. Tal localización está en tensión con la ubicación histórica en tiempos de "príncipes" y "lucha contra moros" de la conquista hispánica, que remite a los "saltos semánticos" de la obra folklórica (Mukarovsky op. cit. ). La fuerza visual de descripciones vinculadas con mutilaciones y heridas es de alto tono efectista, y está conectada con la metonimia de la mutilación corporal, que es la estrategia retórica más relevante. Tal mutilación tiene como contraparte el juego metafórico de condensaciones e identificaciones simbólicas. Es así como la "zorrita" condensa significaciones vinculadas con lo animal y lo sobrenatural, que la identifican con una divinidad protectora. Tal identificación remite a la antítesis entre el bien y el mal, asociada con una contraposición entre esencia y apariencia, y con una dinámica de sustituciones, vinculada con el tópico del engaño. Las brujas, maldiciones, mutilaciones y hechizos remiten a creencias locales. En el nivel léxico, la narradora utiliza un registro coloquial, y recurre a quichuismos como "shulca", para designar a la hija menor, y a giros del habla local como "estar de compras" por "estar embarazada" y "chumar" por "emborrachar". Esto evidencia un trabajo poético que imprime el sello de estilo personal a los estereotipos del discurso tradicional, que incluyen repeticiones asociadas con el uso del complemento especificativo de excelencia, con valor formulaico ("el gusto de los gustos y el sabor de los sabores"). La dinámica entre estereotipo y variación está en correspondencia con la resignificación de un relato de raigambre hispánica, que alude a la lucha contra moros, a la luz de creencias locales que sostienen la intervención de lo sobrenatural en los destinos humanos. Es así como "la zorrita" adquiere un valor metafórico, vinculado con lo sobrenatural celeste, contrapuesta a las brujas y otros seres como "el negro", asociados con lo sobrenatural demoníaco. La dinámica entre estereotipo y variación se evidencia en la alternancia entre un illo tempore remoto, poblado por reyes y príncipes, y el espacio cotidiano de cerros y campos riojanos. La matriz sirve así como pretexto para la incorporación de la cultura local. Las referencias contextuales constituyen de este modo recursos argumentativos, con una particular "retórica del creer" (Palleiro 2008), para persuadir a la audiencia de la verosimilitud del relato.

La representación cultural de un cuerpo femenino fragmentado, asociado con la mutilación y la falta da lugar a una reparación final a través de la unión sexual implicada en el matrimonio con el príncipe. La completud es asociada así con la complementariedad heterosexual, de unión con el representante de un estamento social vinculado con el poder. Las artes de brujería son asociadas con la fragmentación y la falta, reparada mediante un ingreso en un orden social en el cual la unión sexual está regulada por la institución matrimonial.

\section{A modo de cierre}

Analicé aquí la construcción discursiva de la corporalidad 
a partir del tópico de la mutilación, en relatos folklóricos que abarcaron desde la mutilación por un pacto con el diablo en "Media Res", a la caída de los miembros de un cuerpo muerto desde un techo, asociada con una maldición demoníaca en "Cairé", hasta a la mutilación del cuerpo femenino por mediación maléfica de unas brujas, en "La niña sin brazos". Identifiqué una conexión intertextual de las versiones con el discurso ritual, manifiesto en la similitud con casos locales de tratos con el diablo y con el rito de la Salamanca. El trabajo etnográfico me permitió advertir esta vinculación de los relatos con creencias locales e interconectar así distintas especies narrativas. Esta red de conexiones evidenció la recontextualización de matrices generales, articuladas mediante un principio narrativo, en el entorno local.

La construcción retórica de la corporalidad en estos relatos tiene como eje una lógica sinecdótica de tensión entre el todo y la parte, con variedad de matices propia del el estilo personal de cada narrador y de la identidad diferencial del grupo. Dicha lógica remite a procesos metonímicos de fragmentación dispersiva asociados con el quiebre de un orden. La dinámica del cuerpo en pedazos tiene como contrapartida la condensación metafórica de un orden totalizador, que apela a la corporalidad como dimensión simbólica. Las imágenes del cuerpo despedazado pueden asociarse con modalidades cruentas de lesión, que se resuelven en la cura, entendida como recuperación de un "estado oculto de salud" ligado con la restauración de un orden cosmovisional.

El cuerpo aparece en los relatos como soporte sígnico de configuraciones culturales vinculadas con la vida y la muerte, en un contrapunto dialógico. Adquiere así el valor de signo tanto en su dimensión icónica de imagen como en su dimensión indicial de capa metonímica de producción del sentido, que guarda una relación de existencia con el discurso que produce. En efecto, el cuerpo es la dimensión más tangible de la existencia humana, con una fuerza simbólica asociada con representaciones culturales, expresada por los narradores en sus relatos.

\section{Bibliografía}

Buenos Aires, 20 de junio 2016

Aarne, A., S. Thompson. (1928). The types of the folktale: a classification and bibliography, Academia Scientiarum Fennica, Helsinki.

Austin, J. (1982). Cómo hacer cosas con palabras. Paidós, Barcelona.

Bajtín, M. (1979). Estética de la creación verbal. Siglo Veintiuno, México.

Bauman, R. (1975). Verbal art as performance. Waveland Press Inc, Waveland.
Bauman, R. (2004). A world of other's words. Crosscultural perspectives on intertextuality. Blackwell, Cornwall.

Bauman, R. (1974 [1972]). Differential identity and the social base of Folklore. A. Paredes and R. Bauman eds., Toward new perspectives in Folklore, 31-41, The University of Texas Press, Austin and London.

Briggs, Ch., R. Bauman.(1992). Genre, intertextuality and social power. Journal of Linguistic Anthropology, II:131-172.

Briggs, Ch. (2001). Las narrativas en los tiempos del cólera: el color de la muerte en una epidemia venezolana. A. Dupey y M. Poduje eds., Narrar identidades y memorias sociales. Estructura, procesos y contextos de la narrativa folklórica, 1-19, Instituto Nacional de Antropología y Pensamiento Latinoamericano y Ministerio de Cultura y Educación de La Pampa, Santa Rosa.

Bruner, J. (2003). La fábrica de historias. Derecho, literatura, vida. Fondo de Cultura Económica, México.

Citro, S. (2011). Cuerpos plurales. Antropología de y desde los cuerpos, Biblos, Buenos Aires.

Csordas, Th. (2011). Modos somáticos de atención. S. Citro ed., Cuerpos plurales. Antropología de y desde los cuerpos, 83-104, Biblos, Buenos Aires.

Chafe, W. (1990). Some Things That Narratives Tell Us About the Mind. B. K. Britton and A. D. Pellegrini eds., Narrative Thought and Narrative Language, 79-98, Lawrence Erlbaum Associated Publishers, Hove and London.

Chertudi, S. (1978). El cuento folklórico, OMEP, Buenos Aires.

Derrida, J. (1997). Mal de archivo. Una impresión freudiana, Trotta, Madrid.

Douglas, M. (1998). Estilos de pensar, Gedisa, Barcelona.

Gadamer, H.-G. (1996). El estado oculto de la salud, Gedisa, Barcelona.

García Canclini, N. (2001). Culturas híbridas. Estrategias para entrar y salir de la modernidad, Akal, Madrid.

Genette, G. (1974). Fronteras del relato. R. Barthes et al., Análisis estructural del relato, 193-208, Tiempo Contemporáneo, Buenos Aires.

Greimas, A. (1976). Semántica estructural, Gredos, Madrid. 
Greimas, A., J. Courtés. (1982). Semiótica. Diccionario razonado de la teoría del lenguaje, Gredos, Madrid.

Grésillon, A. (1994). Qué es la crítica genética. Filología, XXVII (1-2): 25-52.

Guber, R. (2001). La etnografía, método, campo y reflexividad, Norma Grupo Editorial, Bogotá.

Handler, R., J. Linnekin. (1984). Tradition : genuinous or spurious? Journal of American Folklore, 97 (385): 273290.

Jakobson, R., M. Halle. (1956). Dos aspectos del lenguaje y dos tipos de trastornos afásicos, Fundamentos del lenguaje, 95-102, Ciencia Nueva, Madrid.

Jakobson, R. (1964). Closing Statement: Linguistics and Poetics. Th. Sebeok ed., Style in Language, 350-377, MIT Press, Massachussetts.

Kaliman, R. (2006). Sociología y cultura. Propuestas conceptuales para el estudio del discurso y la reproducción cultural, Facultad de Filosofía y Letras de la Universidad Nacional de Tucumán, San Miguel del Tucumán.

Krmpotic, C. (2011). La naturaleza del lazo social. Reflexiones en torno a la lógica del don en contextos desiguales, Estado, política social y cultura: reflexiones sobre los servicios sociales y de salud, 225-245, Miño y Dávila, Buenos Aires.

Krmpotic, C., M. Palleiro. (2016). Narrativa de creencias, retórica y corporalidad en contextos argentinos. $\mathrm{M}$. Palleiro ed, Cuerpos que narran, 11-18, Ya ediciones, Provincia de Buenos Aires.

Labov, W., J. Waletzky. (1967). Narrative analysis: oral versions of personal experience. J. Helms ed, Essays on the Verbal and Visual Arts, 12-44, University of Washington Press, Seattle and London.

Lausberg, H. (1975). Manual de retórica literaria, Gredos, Madrid.

Le Breton, D. (1995). Antropología del cuerpo y modernidad, Nueva Visión, Buenos Aires.

Le Breton, D. (2002). La sociología del cuerpo, Nueva Visión, Buenos Aires.

Le Galliot, J. (1981). Psicoanálisis y lenguajes literarios. Teoría y práctica, Hachette, Buenos Aires.

Le Guern, M. (1985). La metáfora y la metonimia, Cátedra, Madrid.

Lebrave, J.L.(1990). Déchiffrer, transcrire, éditer la genèse,
Proust à la lettre. Les intermittences de l'écriture ,141162, Du Lérot, Charente.

Mauss, M. (2006). Manual de Etnografía, Fondo de Cultura Económica", Buenos Aires.

Mc. Luhan, M. (1994). Introduction, The medium is the message, Understanding media. The extensions of man, 3-21, Routledge, London.

Menéndez Pidal. (1974). Estudios sobre el Romancero, Obras Completas XI, Madrid.

Merleau Ponty, M. (1984). Fenomenología de la percepción, Planeta, Barcelona.

Mukarovsky, J. (1977). Detail as the basic semantic unit in folk art. J. Burbank, P.Steiner eds, The word and verbal art, 180-204, Yale University Press, New Haven.

Nelson, Th. H. (1992). Literary Machines 90.1, Muzzio Editore, Padova.

Olrik, A. (1992). Principles for Oral Narrative Research, Indiana University Press, Bloomington.

Ong, W. J. (1987). Oralidad y escritura. Tecnologías de la palabra, Fondo de Cultura Económica, México.

Palleiro, M. (1992). Nuevos Estudios de Narrativa Folklórica. En torno a las categorías de "ficción", "historia" y "creencia", Rundinuskín, Buenos Aires.

Palleiro, M. (1993). La dinámica de la variación en el relato oral tradicional riojano. Procedimientos discursivos de construcción referencial de la narrativa folklórica. Síntesis de los planteos principales de la Tesis de Doctorado. Sociocriticism, IX (2, No. 18): 177-182.

Palleiro, M. (2004). Fue una historia real. Itinerarios de un archivo, Instituto de Filología y Literaturas Hispánicas "Amado Alonso" de la Facultad de Filosofía y Letras de la Universidad de Buenos Aires, Buenos Aires.

Palleiro, M. (2007). La Salamanca en representaciones icónicas: performance narrativa y discurso visual. Fernando Fischman e Luciana Hartmann eds., Donos da Palabra: autoria, performance e experiencia em narrativas orais da América do Sul, 157-189, Editora da Universidade Federal de Santa María, Santa María.

Palleiro, M. (2008). Yo creo. Vos ¿sabés? Retóricas del creer en los discursos sociales, Facultad de Filosofía y Letras de la Universidad de Buenos Aires, Buenos Aires.

Palleiro, M., S. Di Marzo, Rita Fabaro, Irene Luque, Mercedes Miño, Lilí Muñoz y Beatriz Suárez Lissi. (2008). Formas del discurso. De la teoría de los signos a las 
prácticas comunicativas, Miño y Dávila, Buenos Aires.

Palleiro, M. comp. (2011). San Patricio en Buenos Aires. Narrativa, celebraciones y migración, Ediciones de la Facultad de Filosofía y Letras de la Universidad de Buenos Aires, Buenos Aires.

Palleiro, M. (2011) "'Los tres deseos': Cuentos maravillosos de la provincia de La Rioja, República Argentina", M. Palleiro ed., Jornada "Archivos de Narrativa Tradicional Argentina" (ANATRA), CD adjunto, Instituto de Filología y Literaturas Hispánicas "Dr. Amado Alonso" de la Universidad de Buenos Aires, Buenos Aires.

Palleiro, M. (2016). El cuento folklórico riojano: una aproximación a la narrativa oral, La Bicicleta ediciones, Buenos Aires.

Peirce, Ch. S. (1987). Obra lógico-semiótica, Taurus, Madrid.'

Pieper, J. (1998). El concepto de pecado, Herder, Barcelona.

Propp, V. (1972). Morfología del cuento, Juan Goyanarte editor, Buenos Aires.

Rappaport, R. (1992). Ritual. R. Bauman ed., Folklore, Cultural Performance and Popular Entertainments. A Communications-centered Handbook, 249-260, Oxford University Press, New York.

Rockwell, E. (1989). Reflexiones sobre el proceso etnográfico. Documento de Investigaciones Educativas, Centro de Investigación y de Estudios Avanzados, México D.F.
Rockwell, E. (2008). Del campo al texto: dilemas del trabajo etnográfico. M. I. Jociles y A. Franzé eds., ¿Es la escuela el problema? Perspectivas socio-antropológicas de etnografía y educación, 89-103, Trotta, Madrid.

Schechner, R. (2000). Performance. Teoría y prácticas interculturales, Secretaría de Extensión Universitaria y Bienestar Estudiantil de la Facultad de Filosofía y Letras de la Universidad de Buenos Aires, Buenos Aires.

Thompson, S. (1958). Motif-Index of Folk-literature, Indiana University Press, Copenhagen and Bloomington.

Turner, V. (1986). The Anthropology of Performance, PAJ Publications, New York.

Turner, V. (1988). El Proceso Ritual, Taurus, Madrid.

Uther, H. (2004). The types of International Folktales: a classification and bibliography, based on the system of Antti Aarne and Stith Thompson, Academia Scientiarum Fennica, Helsinki.

Venturoli, S. (2004). Il paessaggio come testo. La costruzione di un' identità tra territorio e memoria nell' area andina, CLUEB, Bologna.

Verón, E. (1988). Cuerpo significante. L. Rodríguez Illera ed., Educación y comunicación, 41-61, Paidós, Barcelona.

Welter, J. Ch. (1927). L' exemplum dans la littérature religieuse et didactique du Moyen Age, Librairie Occitania-Guitard, Paris et Tolouse. 